
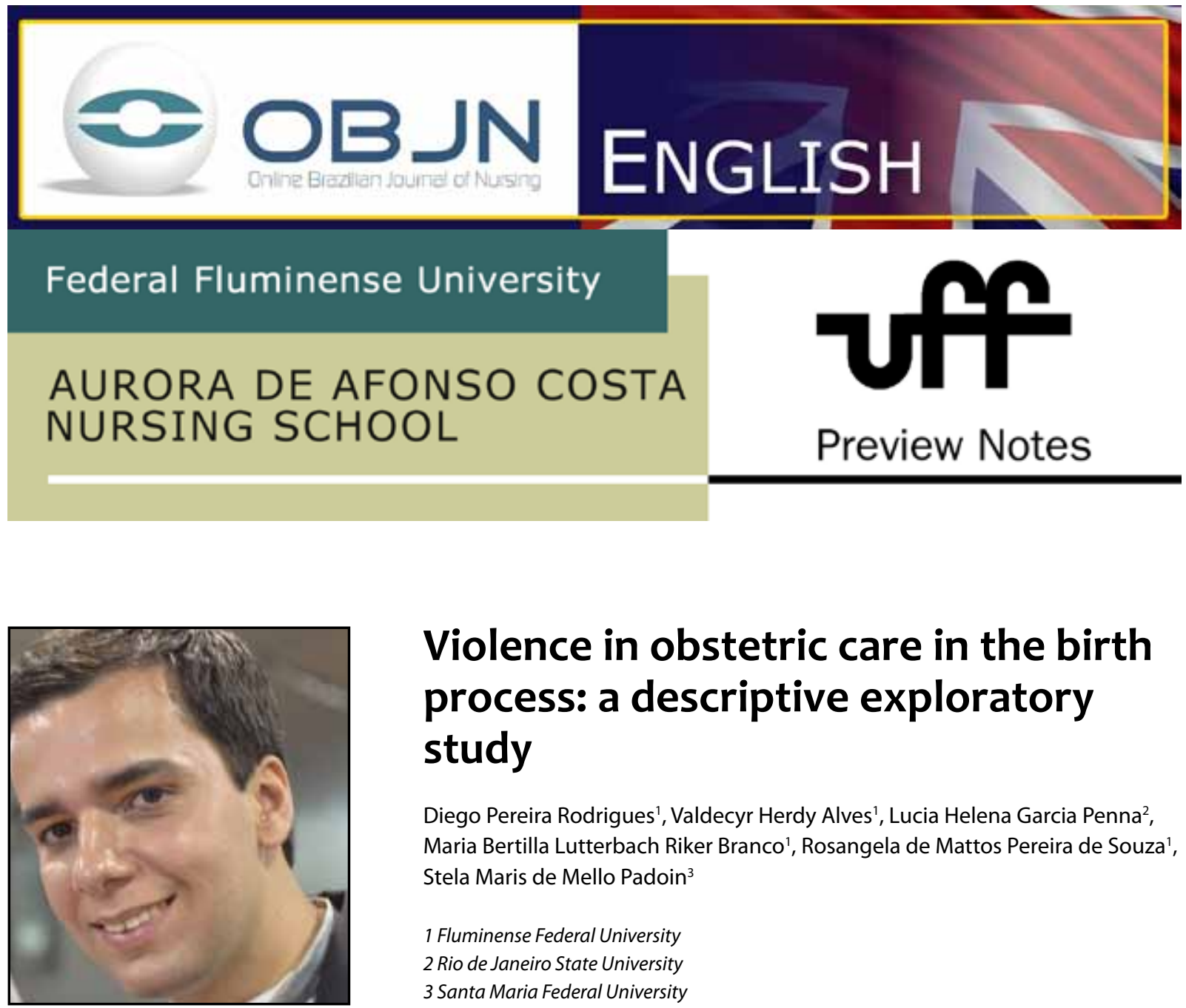

\title{
Violence in obstetric care in the birth process: a descriptive exploratory study
}

Diego Pereira Rodrigues', Valdecyr Herdy Alves', Lucia Helena Garcia Penna², Maria Bertilla Lutterbach Riker Branco', Rosangela de Mattos Pereira de Souza', Stela Maris de Mello Padoin ${ }^{3}$

1 Fluminense Federal University

2 Rio de Janeiro State University

3 Santa Maria Federal University

\section{ABSTRACT}

This is the dissertation project for a Master's Degree in Health Care Science at Fluminense Federal University. The aim is to identify the sociodemographic and obstetric characteristics of pregnant and postpartum women assisted at public hospitals; to characterize the violence experienced during obstetric care as pointed out by pregnant/postpartum women in the birth process from their perspective; to analyze the determinants for the occurrence of this violence in obstetric care from the perspective of pregnant/postpartum women during the labor process. Method: A descriptive, exploratory study, with a qualitative approach, based on semi-structured interviews with women assisted at public hospitals in the Metropolitan II region of the state of Rio de Janeiro, through the analysis of the thematic content that emerged from the interview data.

Descriptors: Violence; Natural Childbirth; Obstetric Nursing. 


\section{SITUATION, PROBLEM AND ITS SIGNIFICANCE}

Violence in assistance with regard to the birth process constitutes a serious problem for women's health. There is evidence that $25 \%$ of Brazilian women have been subject to some form of violence during their labor and delivery ${ }^{(1)}$. This violence is a result of the precariousness of the health system, which also significantly restricts access to the services offered. Such a scenario makes many women in labor undergo a true "pilgrimage" in the search for help within the public health service, with serious risk to their own life and that of their child, due to lack of care in a timely manner ${ }^{(2)}$.

On the other hand, the disregard and disrespect for sexual and reproductive rights, in addition to the human rights of women, allow the imposition of derogatory norms and lax moral values on the part of some health professionals. These norms and values are also identified as being important factors in terms of shaping the complex web of relationships involving the attitudes of violence against women. Mostly, such maltreatment is related to the discriminatory assistance regarding gender, grouped alongside ethnical and social class issues and the permanence of an underlying ideology that naturalizes the social and reproductive condition of the woman with her biological destiny. Consequently, such an ideology indelibly marks a pseudo state of physical and moral inferiority that allows a woman's body and sexuality to be seen as control objects by society and by the medical profession ${ }^{(2)}$.

Accordingly, the Ministry of Health proposes policies such as the Program for the Humanization of Prenatal and Birth (PHPN), and produces publications such as the Humane Care for Women that includes guidelines to ensure improvement in the care provided to women ${ }^{(3)}$.
These guidelines contribute to the humanization of healthcare and allow a reflection upon the performance of health professionals in the context of labor and birth, in order to return to seeing childbirth as a natural physiological and social event, and the role of women in childbirth as the main part with professionals acting as coparticipants in the phenomenon.

\section{GUIDE QUESTIONS}

Is obstetric care in the birth process characterized as violence from the perspective of pregnant/postpartum women? What actions, situations and attitudes developed in the birth process are characterized as violence from the perspective of such women? And how is the care for women in the birth process constituted as being violent in any way, considering the actions recommended by the policy with regard to the humanization of childbirth?

\section{OBJECTIVES}

To identify the socio-demographic and obstetric characteristics of pregnant and postpartum women assisted at public hospitals in Metropolitan II region of the state of Rio de Janeiro; to characterize the violence experienced during obstetric care as pointed out by pregnant/postpartum women in the birth process from their perspective; to analyze the determinants of the occurrence of such violence in obstetric care from the perspective of pregnant/postpartum women during their labor process.

\section{METHOD}

This is a descriptive, exploratory piece of research which adopts a qualitative approach. 
The study participants will be women who have been assisted in the following public hospitals of the Metropolitan Region II of the state of Rio de Janeiro: Antônio Pedro University Hospital, Azevedo Lima State Hospital, Alzira Ferreira Vieira Reis Municipal Maternity, São Gonçalo Women's Municipal Hospital, Conde Modesto Leal Municipal Hospital, Desembargador Leal Junior Municipal Hospital. Fourteen (14) women will be selected in each hospital unit, totaling eighty-four (84) women. However, the saturation process with regard to data will be used. To be included in the sample will be recent postpartum women; women over eighteen (18) years of age; women remaining for twelve (12) hours or more at the general ward unit; women who do not show any physiological and psychological changes that would prevent their participation. The recruitment will be done by a simple random process by selecting charts with odd end numbers. Excluded from study will be women who remained in the labor room, or the pregnant women ward, obstetric center or high-risk ward in public hospitals; women who underwent cesarean delivery, a pathological postpartum or post-abortion. A semi-structured interview will be used as the instrument for data collection. The interviews will be conducted from January to August 2014. Data will be analyzed using the thematic content analysis method.

The study was approved by the Ethics and Research Committee of the Antonio Pedro University Hospital and the College of Medicine, under protocol number 375 252, as recommended in Resolution 466/12 of the National Health Council.

\section{REFERENCES}

1. Fundação Perseu Abramo. Gravidez, Filhos e Violência Institucional no Parto [internet]. 2010 [cited 2013 Nov 22]. Available from: http://www. fpa.org.br/galeria/gravidez-filhos-e-violencia-institucional-no-parto

2. Aguiar JM, D'Oliveira AFPL. Violência institucional em maternidades públicas sob a ótica das usuárias. Interface comun. saúde educ. 2011; 15(36): 79-91.

3. Milfont PM, Silva VM, Chaves DBR, Beltrão BA. An exploratory study on the implementation of guidelines for safe delivery and satisfaction of women. Online Braz J Nurs [Internet]. 2011 [Cited 2013 Oct 5]; 10(3): [12 telas]. DOI: http://dx.doi. org/10.5935/1676-4285.20113493

All authors participated in the phases of this publication in one or more of the following steps, in According to the recommendations of the International Committee of Medical Journal Editors (ICMJE, 2013): (a) substantial involvement in the planning or preparation of the manuscript or in the collection, analysis or interpretation of data; (b) preparation of the manuscript or conducting critical revision of intellectual content; (c) approval of the versión submitted of this manuscript. All authors declare for the appropriate purposes that the responsibilities related to all aspects of the manuscript submitted to OBJN are yours. They ensure that issues related to the accuracy or integrity of any part of the article were properly investigated and resolved. Therefore, they exempt the OBJN of any participation whatsoever in any imbroglios concerning the content under consideration. All authors declare that they have no conflict of interest of financial or personal nature concerning this manuscript which may influence the writing and/or interpretation of the findings. This statement has been digitally signed by all authors as recommended by the ICMJE, whose model is available in http://www. objnursing.uff.br/normas/DUDE_eng_13-06-2013.pdf

Received: 04/12/2014

Revised: 04/30/2014

Approved: 04/30/2014 